\title{
Características químicas do solo com aplicação de água residuária na cultura de alface por diferentes sistemas de irrigação
}

\section{VARIATION OF SOIL CHEMICAL CHARACTERISTICS DUE TO WASTEWATER APPLICATION IN LETTUCE CROP BY IRRIGATION SYSTEMS}

\section{Delvio Sandri(1) \\ Edson E. Matsura(2) \\ Roberto Testezlaf(3)}

${ }^{(1)}$ Dr. em Eng. Agrícola, Pós-doutor UnB, Prof. Nível V da Universidade Estadual de Goiás

${ }^{(2)}$ Dr. em Eng. Agrícola, Prof. Titular. Faculdade de Engenharia Agrícola, Universidade de Campinas

(3) Ph.D. em Eng. Agrícola, Prof. Titular . Faculdade de Engenharia Agrícola, Universidade de Campinas

Endereço: BR 153, n. 3.105, CP 459, 75132-400, Anápolis, GO - Brasil - e-mail: sandri@ueg.br.

\section{RESUMO}

Objetivou-se avaliar a variação dos constituintes químicos do solo, nas camadas de 0-0,10 m e 0,100,20 m, devido à aplicação de água residuária, comparando com água proveniente de um depósito de fonte superficial, durante dois ciclos da alface (Lactuca sativa L.), cV "Elisa", utilizando os sistemas de irrigação por aspersão, gotejamento subterrâneo e superficial. A concentração de sódio no $1^{\circ}$ ciclo elevou-se nos tratamentos irrigados com água residuária, em ambas as camadas de solo; enquanto que o manganês elevou-se na camada de 0-0,10 m na irrigação por aspersão e gotejamento superficial. No $2^{\circ}$ ciclo os tratamentos irrigados com água residuária apresentaram elevação do nitrogênio total. A irrigação com água residuária manteve os constituintes químicos do solo dentro dos limites aceitáveis, não apresentando, de maneira geral, correlação entre os parâmetros químicos do solo e os sistemas de irrigação.

\section{ABSTRACT}

The purpose is to evaluate the variation of soil chemical constituents, in the soil layers of 0-0,10 m and 0,10-0,20 m, due to wastewater and surface water reservoir applications, during two cycles of the lettuce crop (Lactuca sativa L.), cv "Elisa", using sprinkle, surface and subsurface drip irrigation systems. The elevation of sodium concentration in the 1st cycle for the treatments irrigated with wastewater, in both soil layers; the manganese concentration increased in this 1 st cycle at the soil layer of 0-0,10 $\mathrm{m}$ for the sprinkler and surface drip irrigation. In the 2nd cycle, the treatments with wastewater presented an elevation of total nitrogen. The wastewater irrigation kept the analyzed soil chemical constituents within the acceptable levels, it was not observed correlation between the variations of soil chemical parameters and irrigation systems.

Palavras-chave: irrigação; características químicas do solo; água residuária.

Keywords: irrigation; chemical characteristics of soil; wastewater.

\section{INTRODUÇÃO}

A irrigação de culturas com água residuária foi introduzida inicialmente em propriedades rurais na Europa, América do Norte e Austrália, tornando-se popular em fins do século XIX e início do século XX. Porém com o desenvolvimento de modernos sistemas de tratamento das águas residuárias e da preocupação com a contaminação por microrganismos, houve significativa redução do uso destas águas para fins de irrigação, tornando-se menos popular e praticamente desaparecendo por completo logo após a Primeira Guerra Mundial (STEIN e SCHWARTZBROD, 1990).

Nas duas últimas décadas, houve um aumento na retomada desta prática, tanto em países industriali- 
zados como em desenvolvimento, devido a fatores como a escassez de água, especialmente em zonas áridas, semi-áridas e em regiões subtropicais, onde ocorre elevada concentração populacional e industrial, resultando em maior demanda de oferta de água, reconhecimento da presença de nutrientes no esgoto doméstico, reduzindo as despesas com fertilizantes, custo elevado das estações de tratamentos avançados de efluentes, melhor aceitação sócio-cultural e reconhecimento do valor desta prática como responsável pelo planejamento, melhor uso da água e do avanço tecnológico. Novos projetos de disposição e reuso de água residuária são verificados todos os anos em várias regiões do mundo como na China, Oriente Médio e região do Mediterrâneo, América do Sul, Estados Unidos, dentre outros (ANDRADE NETO, 1992 e FRIEDLER et al. 1996).

Segundo Tarchitzky et al. (2007) a utilização de águas residuárias tratadas para irrigação das culturas é uma alternativa para substituição do uso água natural, válido para todos os paises nos quais a água é escassa. Em regiões áridas e semi-áridas, o uso de águas residuárias permitiu disponibilizar maiores quantidades de água natural para uso doméstico.

A aplicação de efluentes ao solo é vista como forma efetiva de controle da poluição e uma alternativa viável para aumentar a disponibilidade hídrica em regiões áridas e semi-áridas podendo reduzir os custos com tratamento e ainda servir como fonte de nutriente para as plantas reduzindo, assim, os custos, com a aquisição de fertilizantes químicos comerciais (MEDEIROS et al., 2005).

A aplicação de efluente secundário na irrigação por gotejamento de tomate, pimenta, cebola, pepino, feijão e melão, foi estudado por Neilsen et al. (1989), concluindo que após 4 anos de irrigação, o conteúdo de sódio nos primeiros $0,30 \mathrm{~m}$ de solo, não foi prejudicial para as culturas. A camada de solo de 0-0,15 m apresentou menor valor de cálcio trocável e maior de magnésio não trocável e uma grande mudança na concentração de sódio trocável, quando comparada ao solo irrigado com água superficial. A condutividade elétrica não foi afetada, entretanto, a longo tempo de uso de efluentes, requererá monitoramento do balanço de cátions no solo, restringindo a solubilidade de muitos micronutrientes, incluindo o zinco.

Em um outro trabalho Jnad et al., (2001a), analisaram as mudanças nas características químicas do solo devido a aplicação de efluente tratado em tanque séptico (tratamento primário) seguido de leitos cultivados com macrófitas (tratamento avançado) utilizando o gotejamento subterrâneo como sistema de disposição no solo em quatro locais diferentes. Constatou que a aplicação de água residuária resultou em aumento significativo de sódio no solo quando a concentração do mesmo no efluente era alta, e a concentração inicial no solo era baixa. A concentração de $\mathrm{P}$ aumentou significativamente próximo do emissor e na superfície do solo, por estar a linha de gotejador instalada a uma profundidade pequena. Não houve uma mudança drástica na concentração de nitrogênio total, Ca, Mg, K, carbono orgânico total e no conteúdo de sais no perfil do solo. Ainda de acordo com estes autores, a aplicação de água residuária utilizando a irrigação por gotejamento subterrâneo é relativamente recente, por isso poucas informações são encontradas sobre o impacto do uso deste tipo de água sobre as propriedades químicas do solo nas vizinhanças do emissor.

De uma maneira geral segundo Leal et al. (2009), a irrigação com águas residuárias pode beneficiar as culturas agrícolas com água e nutrientes essenciais (especialmente nitrogênio), observaram mudanças de pequena magnitude no $\mathrm{pH}$ e de outros cátions trocáveis do solo ao longo do tempo de irrigação da cultura da cana-de-açúcar. Observam que a irrigação com águas residuárias deverá adquirir importâncias crescentes, exigindo atenção detalhada ao balanço entre o aporte de nutrientes via irrigação e as quantidades requeridas para a otimização da produtividade da cultura.

Para Duarte et al. (2008) a irrigação com esgoto sem tratamento adequado pode afetar a fauna e flora, transmitir doenças pelo contato com os trabalhadores e contaminação das culturas irrigadas, pode causar toxidade do solo, contaminação dos aqüíferos, especialmente por nitratos. Neste sentido é muito impor-

Figura 1 - Diferentes métodos de aplicação de água de irrigação (adaptado, FAO 1988 ).

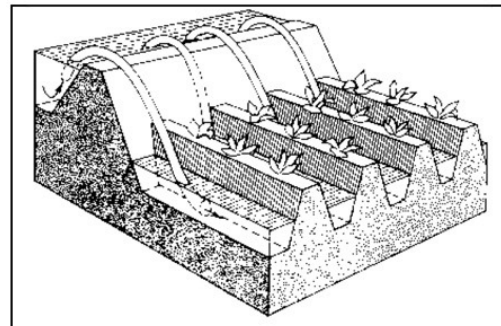

(a) Irrigação por sulcos

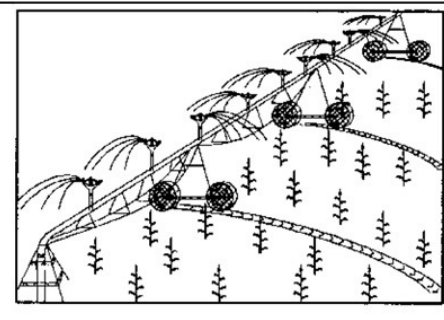

(b) Irrigação por aspersão por pivô central

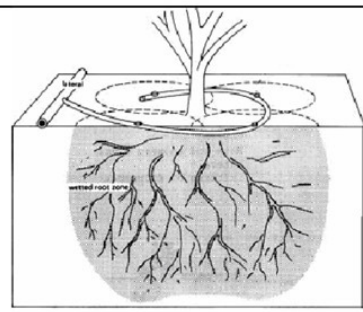

(c) Irrigação localizada por gotejamento 
tante conhecermos as diferentes maneiras de aplicação da água residuária a partir da irrigação. Podemos dividir a irrigação baseada na quantidade de água aplicada e tipos de equipamentos empregados. Desta forma teremos a irrigação por gravidade ou superfície, por aspersão e localizada. Estes métodos são ilustrados pelas Figuras la, b e c, onde podemos verificar a forma de distribuição de água na planta e no solo.

Um dos primeiros métodos de aplicação de água residuária utilizado foi a da irrigação por superfície devido ao custo baixo de aplicação e tecnologia empregada. No entanto este método tinha alguns problemas como o odor exalado e o pouco controle da água, provocando a perda por percolação profunda. O método é ainda bastante utilizado em condições topográficas adequadas e, sobretudo com água residuárias oriunda da suinocultura e das agroindústrias. O segundo método de aplicação, o de aspersão possui a característica de distribuição de água, imitando a chuva e seu uso contempla as culturas que sua parte aérea não são comestíveis.

Segundo Armon et al. (1994), a irrigação de culturas sem controle com efluentes pode se tornar um dos principais problemas de saúde pública. Um estudo feito por estes autores, utilizando a irrigação por aspersão para as culturas da alface, salsa, flores, couve, cebola, cenoura, rabanete e tomate, com dois tipos de efluentes, mostrou uma clara correlação entre a qualidade do efluente e o grau de contaminação nos vegetais irrigados com efluentes altamente contaminados por coliformes fecais e Salmonella spp. A irrigação por aspersão pode aumentar os efeitos contaminantes nas culturas devido ao alto contato entre o efluente e o vegetal.

A irrigação por aspersão com água residuária é mais perigosa que outros métodos em termos de saúde pública. Pode formar aerossóis, contendo microrganismos, que são transportados pelo vento a distâncias superiores a um quilômetro, causando riscos a saúde das pessoas devido a inalação de patógenos presentes nos aerossóis (SCALOPPI e BAPTISTELLA, 1986).

Dentre todos os métodos de irrigação, a localizada possui características importantes para a aplicação de água residuária por propiciar uma melhor eficiência de aplicação, reduzindo a possibilidade de contaminação das culturas, porém, está sujeita a entupimentos, exigindo a filtração da água antes de atingir os gotejadores. Este método permite o uso da fertirrigação, ou seja, a aplicação de fertilizantes na água de irrigação. Segundo Bastos et al. (2003), na fertirrigação a aplicação de fertilizantes é monitorada, de maneira a permitir o seu parcelamento, nos diversos estágios da cultura, suprindo suas necessidades nutricionais. Desta forma as águas residuárias de esgoto domestico pode ser uma fonte complementar de nutrientes as plantas.

Nas propriedades localizadas no "cinturão verde" do município de Campinas, SP e outros grandes centros urbanos do Brasil, são cultivadas várias hortaliças, a maioria de ciclo curto, sendo a alface a que apresenta maior importância econômica, pois compreende a hortaliça folhosa de maior produção e consumo, visto que, a nível de Estado de São Paulo o consumo per capita foi estimado em $2 \mathrm{~kg}$ por pessoa ao ano, sendo $40 \%$ dos seus gastos totais com verduras destinados à compra da alface, além da importância nutricional, já que, encontra-se presente regularmente na dieta da população brasileira

Dado as características dos métodos de aplicação de água de irrigação, este trabalho teve como objetivo conhecer as características químicas do solo, de uma cultura de alface irrigada partir de uma água residuária tratada com leitos cultivados com macrófitas e água do depósito de fonte hídrica superficial. Os seguintes métodos de irrigação foram utilizados: por aspersão, gotejamento subterrâneo e superficial.

\section{METODOLOGIA}

O trabalho foi desenvolvido na Faculdade de Engenharia Agrícola (FEAGRI/UNICAMP), Campinas, SP, com Latitude de $22^{\circ} 53^{\prime} \mathrm{S}$ e Longitude de $47^{\circ} 05^{\prime}$. O solo foi classificado como Latossolo Vermelho Distroférrico A textura do solo na camada de 0-0,20 m, foi classificada como argilosa (56,9\% de argila, 19,2\% de silte e $23,9 \%$ de areia). Realizou-se dois ciclos da cultura da alface (Lactuca sativa L.) cv Elisa, compreendendo os períodos de 08/06 a 23/07/01 ( $1^{\circ}$ ciclo) e de 17/ 08 a 03/10/2001 ( $2^{\circ}$ ciclo). O clima, segundo a classificação de Köppen, é uma transição entre Cwa e Cwf, isto é, subtropical de altitude, seco no inverno e chuvoso e quente no verão, com precipitação média anual em torno de $1370 \mathrm{~mm}$, temperatura média anual de $21,7^{\circ} \mathrm{C}$ e umidade relativa do ar de $66,2 \%$.

A aplicação de água para a cultura foi diária, determinando-se a lâmina de irrigação a partir da evapotranspiração de referência do dia anterior, obtida pela equação de Penman-Monteith a partir de dados de uma estação climática automática, instalada a 150 metros do local do experimento. Utilizaram-se os sistemas de irrigação por aspersão (aspersores com vazão de 0,45 $\mathrm{m}^{3} \mathrm{~h}^{-1}$, espaçados de 12,00 x 12,00 m) e gotejamento subterrâneo e superficial (utilizaram-se duas linhas de gotejadores tipo labirinto por canteiro, totalizando 6 linhas de gotejadores por tratamento, com espaçamento entre emissores na linha lateral de $0,40 \mathrm{~m}$ e vazão de $2,3 \mathrm{~L} \mathrm{~h}^{-1}$ ). No gotejamento subterrâneo as linhas laterais foram enterradas a uma profundidade de 0,10 $\mathrm{m}$ da superfície do solo.

O monitoramento químico do solo e da água de irrigação foi realizado nos dias 6, 26 e 46 após o transplantio (DAT) para o $1^{\circ}$ ciclo e aos 7, 27 e 49 DAT para o $2^{\circ}$ ciclo. Foram coletadas amostras de solo nas profundidades de 0-0,10 m e 0,10-0,20 m, no início, no
3

agosto/09 
meio e no final de cada canteiro, que foram misturadas e resultaram em três amostras compostas (uma por canteiro) por camada estudada. O local de coleta das amostras de solo no canteiro foi sempre entre duas plantas de alface, em uma das linhas de plantas centrais consideradas úteis. Os sistemas de tratamento, assim como a rede de distribuição de água com as duas qualidades usadas são apresentados pela Figura 2 e

Tabela 1 - Análise da água residuária e do depósito superficial utilizada na irrigação por aspersão e gotejamento subterrâneo e superficial durante $01^{\circ}$ ciclo aos 06, 26 e 46 DAT.

\begin{tabular}{|c|c|c|c|c|c|c|}
\hline \multirow[b]{3}{*}{ Parâmetro } & \multicolumn{6}{|c|}{ Aspersão } \\
\hline & \multicolumn{3}{|c|}{ Água residuária } & \multicolumn{3}{|c|}{ Água do depósito } \\
\hline & 06 & 26 & 46 & 06 & 26 & 46 \\
\hline & \multicolumn{6}{|c|}{ mg. $\mathrm{L}^{-1}$} \\
\hline Dureza & 100,7 & 87,3 & 85,7 & 21,15 & 18,2 & 20,7 \\
\hline Enxofre & 2,0 & 3,0 & 3,0 & 1,0 & 1,0 & 1,0 \\
\hline Ferro & 0,5 & 0,5 & 2,0 & 0,8 & 0,6 & 0,3 \\
\hline Boro & 0,1 & 0,1 & 0,1 & * & * & * \\
\hline $\mathrm{P}$ total & 1,65 & 2,10 & 1,30 & 0,02 & 0,15 & 0,01 \\
\hline $\mathrm{P}_{2} \mathrm{O}_{5}$ & 3,75 & 4,85 & 2,80 & 0,05 & 0,34 & 0,03 \\
\hline $\mathrm{NH}_{4}^{+}-\mathrm{N}$ & 26,50 & 31,50 & 28,75 & 0,00 & 0,00 & 0,00 \\
\hline $\mathrm{NO}_{3}^{-}-\mathrm{N}$ & 0,3 & 0,0 & 0,4 & 0,3 & 0,0 & 0,4 \\
\hline Sólidos suspensos totais & 13 & 4 & 18 & 2 & 2 & 3 \\
\hline $\mathrm{DBO}_{5}$ & 28 & 0 & 55 & 0 & 0 & 0 \\
\hline DQO & 46 & 5 & 124 & 2 & 0 & 14 \\
\hline Sólidos dissolvidos totais ${ }^{1}$ & 323,8 & 290,6 & 331,5 & 33,9 & 24,3 & 30,7 \\
\hline Sódio (meq. $\mathrm{L}^{-1}$ ) & 0,78 & 0,83 & 0,78 & 0,04 & 0,09 & 0,09 \\
\hline Cálcio (meq. $\mathrm{L}^{-1}$ ) & 1,85 & 1,50 & 1,55 & 0,30 & 0,20 & 0,25 \\
\hline Magnésio (meq. $\mathrm{L}^{-1}$ ) & 0,17 & 0,25 & 0,17 & 0,13 & 0,17 & 0,17 \\
\hline Potássio (meq. $\mathrm{L}^{-1}$ ) & 0,23 & 0,23 & 0,28 & 0,03 & * & 0,01 \\
\hline $\operatorname{RAS}\left(\mathrm{mmol}_{\mathrm{c}} \mathrm{L}^{-1}\right)^{1 / 2}$ & 0,78 & 0,88 & 0,84 & 0,09 & 0,20 & 0,19 \\
\hline $\mathrm{CE}\left(\mathrm{dS} . \mathrm{m}^{-1}\right)$ & 0,51 & 0,45 & 0,52 & 0,05 & 0,04 & 0,05 \\
\hline Turbidez (FAU) & 22 & 5 & 35 & 4 & 4 & 6 \\
\hline \multirow[t]{2}{*}{$\mathrm{pH}$} & 7,3 & 7,3 & 7,1 & 6,4 & 7,2 & 6,7 \\
\hline & \multicolumn{6}{|c|}{ Gotejamento subterrâneo e superficial } \\
\hline Dureza & 98,2 & 78,2 & 88,2 & 28,65 & 20,7 & 23,2 \\
\hline Enxofre & 2,0 & 2,0 & 1,0 & 1,0 & 1,0 & 1,0 \\
\hline Ferro & 0,3 & 0,8 & 1,5 & 0,9 & 0,7 & 0,4 \\
\hline Boro & 0,1 & 0,1 & 0,1 & * & * & * \\
\hline$P$ total & 1,60 & 1,45 & 1,10 & 0,02 & 0,04 & 0,01 \\
\hline $\mathrm{P}_{2} \mathrm{O}_{5}$ & 3,60 & 3,40 & 2,60 & 0,02 & 0,10 & 0,03 \\
\hline $\mathrm{NH}_{4}^{+}-\mathrm{N}$ & 24,00 & 32,00 & 30,50 & 0,00 & 0,00 & 0,00 \\
\hline $\mathrm{NO}_{3}^{-}-\mathrm{N}$ & 0,5 & 0,1 & 0,5 & 0,3 & 0,0 & 0,4 \\
\hline Sólidos suspensos totais & 42 & 12 & 100 & 1 & 3 & 3 \\
\hline $\mathrm{DBO}_{5}$ & 33 & 6 & 22 & 3 & 0 & 0 \\
\hline DQO & 9 & 8 & 62 & 0 & 0 & 0 \\
\hline Sólidos dissolvidos totais ${ }^{1}$ & 323,8 & 283,5 & 332,8 & 33,9 & 25,6 & 34,6 \\
\hline Sódio (meq. $\mathrm{L}^{-1}$ ) & 0,65 & 0,74 & 0,87 & 0,04 & 0,09 & 0,09 \\
\hline Cálcio (meq. $\mathrm{L}^{-1}$ ) & 1,80 & 1,40 & 1,60 & 0,45 & 0,25 & 0,30 \\
\hline Magnésio (meq. $\mathrm{L}^{-1}$ ) & 0,17 & 0,17 & 0,17 & 0,13 & 0,17 & 0,17 \\
\hline Potássio (meq. $\mathrm{L}^{-1}$ ) & 0,21 & 0,23 & 0,28 & 0,03 & * & 0,01 \\
\hline $\operatorname{RAS}\left(\mathrm{mmol}_{\mathrm{c}} \mathrm{L}^{-1}\right)^{1 / 2}$ & 0,66 & 0,84 & 0,93 & 0,08 & 0,19 & 0,18 \\
\hline $\mathrm{CE}\left(\mathrm{dS} . \mathrm{m}^{-1}\right)$ & 0,51 & 0,44 & 0,52 & 0,05 & 0,04 & 0,05 \\
\hline Turbidez (FAU) & 54 & 8 & 43 & 4 & 1 & 6 \\
\hline $\mathrm{pH}$ & 7,2 & 7,4 & 7,1 & 6,8 & 7,1 & 7,1 \\
\hline
\end{tabular}

Figura 3, descrito abaixo.

Para cada sistema de irrigação foram construídos 3 canteiros (repetições), com 1,20 m de largura, 10,0 $\mathrm{m}$ de comprimento e $0,2 \mathrm{~m}$ de altura, no mesmo local durante os dois ciclos. Foram incorporados na camada de $0-0,20 \mathrm{~m}$, tanto no $1^{\circ}$ como no $2^{\circ}$ ciclos, $33 \mathrm{~kg}$ ha $^{-1}$ de $\mathrm{N}, 116 \mathrm{~kg} \mathrm{ha}^{-1}$ de $\mathrm{P}_{2} \mathrm{O}_{5}$ e $67 \mathrm{~kg} \mathrm{ha}^{-1}$ de $\mathrm{K}_{2} \mathrm{O}$, considerando-se a recomendação de Trani e van Raij (1997) e mais 20,8 toneladas por ha de um condicionador de solo à base de turfa. Em cobertura foram aplicados, por vez, $15 \mathrm{~g} \mathrm{~m}^{-2}$ de sulfato de amônia com $20 \%$ de $\mathrm{N}$, aos 20 e 32 dias após o transplantio (DAT) no $1^{\circ}$ ciclo e aos 10,20 e 32 DAT no $2^{\circ}$ ciclo. Constatou-se, no $1^{\circ}$ ciclo uma precipitação de $40 \mathrm{~mm}$, concentrada na última semana antes do final do mesmo, enquanto no $2^{\circ}$ ciclo foi de $197 \mathrm{~mm}$, distribuídos ao longo do ciclo da cultura.

Utilizou-se água residuária tratada com tanques sépticos modificados seguidos por leitos cultivados com macrófitas e água proveniente de depósito superficial, sendo a água coletada após o sistema de filtragem para a irrigação por gotejamento (Tabelas 1 e 2).

Os elementos químicos analisados no solo foram fósforo, potássio, sódio, nitrogênio total, manganês, cálcio, magnésio e sais totais. A técnica de determinação analítica utilizada seguiu os procedimentos descritos por Silva (1999). A avaliação estatística foi realizada comparando-se os valores médios dos tratamentos, independentemente dos sistemas de irrigação, apenas em função das épocas de coleta das amostras de solo $(6,26$ e 46 dias após o transplantio - DAT para o $1^{\circ}$ ciclo e aos 7, 27 e 49 dias após o transplantio para o $2^{\circ}$ ciclo).

\section{RESULTADOS E DISCUSSÃO}

O valor máximo na água residuária de $\mathrm{Ca}^{2+}$ foi de 1,85 meq $\mathrm{L}^{-1}$ no $1^{\circ}$ ciclo e de 1,55 meq $\mathrm{L}^{-1}$ no $2^{\circ}$ no ciclo, enquanto que o $\mathrm{Na}^{2+}$ foi de 0,87 meq $\mathrm{L}-1$ e o $\mathrm{Mg}^{2}$ + foi de 0,25 meq L-1 ${ }^{-1}$ tanto no $1^{\circ}$ ciclo como no $2^{\circ}$ ciclos (Tabelas 1 e 2), valores considerados normais para água de irrigação segundo Ayers e Westcot (1991). O valor da RAS considerando-se os dois ciclos foi de

* Abaixo do limite de detecção; 1 Fonte: PAGANINI (1997), CE = condutividade elétrica, SDT(mg.L-1) = CE (dS.m-1) x 640 . no máximo $0,97 \mathrm{mmolc}^{-1}{ }^{1 / 2}$ para a água residuária e de 0,23 mmolc $\mathrm{L}^{-11 / 2}$ para a água do depósito, não de- 
vendo causar efeitos negativos ao solo (Ayers e Westcot, 1991), sendo adequado entre 4,5 a 7,9 $\mathrm{mmol}_{\mathrm{c}} \mathrm{L}^{-1}$ 1/2 (FEIGIN et al., 1991). Os valores de $\mathrm{N}-\mathrm{NH} 4+$ foram considerados críticos na água residuária para irrigação de hortaliças, com média de $28,9 \mathrm{mg} \mathrm{L}^{-1}$ no $1^{\circ}$ ciclo e de $28,8 \mathrm{mg} \mathrm{L}^{-1}$ no $2^{\circ}$ ciclo (TRANI, 2001), enquanto na água do depósito não se detectou sua presença. Na irrigação de hortaliças consumidas cruas o

Tabela 2 - Qualidade da água residuária e do depósito superficial utilizada na irrigação por aspersão e gotejamento subterrâneo e superficial no $2^{\circ}$ ciclo aos 10, 25 e 47 DAT.

\begin{tabular}{|c|c|c|c|c|c|c|}
\hline \multirow[b]{3}{*}{ Parâmetro } & \multicolumn{6}{|c|}{ Aspersão } \\
\hline & \multicolumn{3}{|c|}{ Água residuária } & \multicolumn{3}{|c|}{ Água do depósito } \\
\hline & 10 & 25 & 47 & 10 & 25 & 47 \\
\hline & \multicolumn{6}{|c|}{ - mg. $\mathrm{L}^{-1}$ - } \\
\hline Dureza & 78,2 & 83,2 & 89,8 & 18,2 & 15,7 & 18,2 \\
\hline Enxofre & 3,0 & 3,0 & 4,0 & 1,0 & 1,0 & 2,0 \\
\hline Ferro & 1,0 & 0,7 & 0,5 & 0,4 & 0,9 & 0,9 \\
\hline Boro & * & 0,1 & 0,1 & * & * & 0,4 \\
\hline$P$ total & 1,50 & 2,60 & 1,50 & 0,05 & 0,02 & 0,13 \\
\hline $\mathrm{P}_{2} \mathrm{O}_{5}$ & 3,41 & 5,90 &, 41 & 0,12 & 0,04 & 0,32 \\
\hline $\mathrm{NH}_{4}^{+}-\mathrm{N}$ & 35,75 & 32,25 & 36,00 & 0,00 & 0,00 & 0,00 \\
\hline $\mathrm{NO}_{3}^{-}-\mathrm{N}$ & 0,6 & 1,0 & 0,2 & 0,2 & 0,4 & 0,2 \\
\hline Sólidos suspensos totais & 6,0 & 4,0 & 5,0 & 7,0 & 9,0 & 7,0 \\
\hline $\mathrm{DBO}_{5}$ & ** & ** & ** & ** & ** & ** \\
\hline DQO & 28,0 & 59,0 & 7,0 & 21,0 & 37,0 & 0,0 \\
\hline Sólidos dissolvidos totais $^{1}$ & 325,1 & 327,7 & 390,4 & 31,4 & 28,8 & 30,7 \\
\hline Sódio (meq. $\mathrm{L}^{-1}$ ) & 0,78 & 0,83 & 0,78 & 0,09 & 0,09 & 0,04 \\
\hline Cálcio (meq. $\mathrm{L}^{-1}$ ) & 1,40 & 1,50 & 1,55 & 0,20 & 0,15 & 0,20 \\
\hline Magnésio (meq. $\mathrm{L}^{-1}$ ) & 0,17 & 0,17 & 0,25 & 0,17 & 0,17 & 0,17 \\
\hline Potássio (meq. $\mathrm{L}^{-1}$ ) & 0,21 & 0,28 & 0,31 & 0,01 & 0,01 & 0,03 \\
\hline $\operatorname{RAS}\left(\mathrm{mmol}_{\mathrm{c}} \mathrm{L}^{-1}\right)^{1 / 2}$ & 0,88 & 0,90 & 0,82 & 0,20 & 0,22 & 0,10 \\
\hline $\mathrm{CE}\left(\mathrm{dS} \cdot \mathrm{m}^{-1}\right)$ & 0,51 & 0,51 & 0,61 & 0,05 & 0,05 & 0,05 \\
\hline Turbidez (FAU) & 7 & 3 & 9 & 9 & 12 & 14 \\
\hline \multirow[t]{2}{*}{$\mathrm{pH}$} & 7,2 & 7,3 & 7,4 & 6,7 & 6,9 & 6,6 \\
\hline & \multicolumn{6}{|c|}{ Gotejamento subterrâneo e superficial } \\
\hline Dureza & 84,8 & 83,2 & 87,3 & 20,7 & 18,2 & 18,2 \\
\hline Enxofre & 2,0 & 3,0 & 4,0 & 1,0 & 1,0 & 3,0 \\
\hline Ferro & 1,1 & 0,8 & 0,5 & 0,4 & 0,9 & 0,9 \\
\hline Boro & * & 0,1 & 0,1 & * & * & 0,2 \\
\hline$P$ total & 1,60 & 2,10 & 1,40 & 0,18 & 0,02 & 0,13 \\
\hline $\mathrm{P}_{2} \mathrm{O}_{5}$ & 3,40 & 4,80 & 3,25 & 0,42 & 0,05 & 0,31 \\
\hline $\mathrm{NH}_{4}^{+}-\mathrm{N}$ & 36,50 & 32,75 & 38,75 & 0,00 & 0,00 & 0,00 \\
\hline $\mathrm{NO}_{3}^{-}-\mathrm{N}$ & 1,0 & 1,3 & 0,3 & 0,3 & 0,3 & 0,1 \\
\hline Sólidos suspensos totais & 4,0 & 2,0 & 8,0 & 8,0 & 2,0 & 5,0 \\
\hline $\mathrm{DBO}_{5}$ & ** & $* *$ & ** & ** & ** & $\star \star$ \\
\hline DQO & 18,0 & 47,0 & 2,0 & 9,0 & 47,0 & 0,0 \\
\hline Sólidos dissolvidos totais ${ }^{1}$ & 333,4 & 336,0 & 409,6 & 37,1 & 32,0 & 30,7 \\
\hline Sódio (meq. $\mathrm{L}^{-1}$ ) & 0,78 & 0,87 & 0,83 & 0,09 & 0,09 & 0,04 \\
\hline Cálcio (meq. $\mathrm{L}^{-1}$ ) & 1,45 & 1,50 & 1,50 & 0,25 & 0,20 & 0,20 \\
\hline Magnésio (meq. $\mathrm{L}^{-1}$ ) & 0,25 & 0,17 & 0,25 & 0,17 & 0,17 & 0,17 \\
\hline Potássio (meq. $\mathrm{L}^{-1}$ ) & 0,26 & 0,28 & 0,31 & 0,01 & 0,01 & 0,03 \\
\hline $\operatorname{RAS}\left(\mathrm{mmol}_{\mathrm{c}} \mathrm{L}^{-1}\right)^{1 / 2}$ & 0,85 & 0,95 & 0,88 & 0,19 & 0,20 & 0,10 \\
\hline$C E\left(d S \cdot m^{-1}\right)$ & 0,52 & 0,53 & 0,64 & 0,06 & 0,05 & 0,05 \\
\hline Turbidez (FAU) & 3 & 7 & 14 & 10 & 5 & 12 \\
\hline $\mathrm{pH}$ & 7,2 & 7,4 & 7,3 & 7,0 & 7,2 & 7,2 \\
\hline
\end{tabular}

limite do nitrogênio amoniacal para $\mathrm{pH}=7,5$, situação deste trabalho, é de $3,5 \mathrm{mg} \mathrm{L}^{-1}$; assim, os resultados obtidos estão acima dos padrões recomendados. Os valores normais de $\mathrm{N}-\mathrm{NH}_{4}{ }^{+}$em água de irrigação estão entre 0 e 5,0 $\mathrm{mg} \mathrm{L}^{-1}$, nas em águas residuais domésticas ou das fábricas processadoras de alimentos, estão entre 10 e $50 \mathrm{mg} \mathrm{L}^{-1}$. Os parâmetros $\mathrm{S}, \mathrm{Fe}, \mathrm{B}, \mathrm{K}$, $\mathrm{P}$ total, $\mathrm{P}_{2} \mathrm{O}_{5}, \mathrm{~N}-\mathrm{NO}_{3}{ }^{-}$, DOO, SDT, EC e pH, apresentaram valores dentro dos níveis aceitáveis para água de irrigação (AYERS \& WESTCOT, 1991). Observa-se nas Tabelas 1 e 2 que o pH médio foi ligeiramente básico para a água residuária, em ambos os ciclos da alface, sendo que nas águas a serem utilizadas para irrigação, segundo os autores acima, recomendam que o valor se encontre entre 6,5 a 8,4, portanto, dentro do aceitável. Conforme Duarte et al. (2008) a concentração $\mathrm{H}^{+}$e $\mathrm{OH}^{-}$, contida nas águas de irrigação, pode exercer influência na disponibilidade e absorção de nutrientes por parte das plantas, na estrutura e propriedades do solo e nos sistemas de irrigação.

Nota-se uma mudança não regular dos valores de $\mathrm{P}$ entre as épocas de coleta de solo, em ambas as camadas analisadas, que pode ser atribuída ao fato de não se ter considerado a posição de coleta das amostras de solo em relação ao emissor e, sim, somente uma distância em relação à lateral de gotejadores que em virtude da baixa mobilidade no solo (Tabela 3). Nos tratamentos Gbr, Gbd, Gpr e Gpd no $1^{\circ}$ ciclo, de maneira geral, houve tendência de elevação de $\mathrm{P}$, embora não significativo, até aos $26 \mathrm{DAT}$, reduzindo aos $46 \mathrm{DAT}$, podendo ter sido influenciado pela absorção deste íon pela alface na segunda metade de seu ciclo, concordando com Duarte et al. (2008). Resultados contrários foram observados por Kouraa et al. (2002), quando irrigaram batatinha e alface com esgoto bruto, água residuária tratada e água potável, onde depois de um ano de cultivo não houve alterações nos teores de fósforo do solo, sendo que para ocorrer mudanças nas características químicas do solo, relatam que são necessários vários anos de irrigação, visto que a dinâmica deste ocorre muito lentamente.

Observou-se redução significativa de $\mathrm{K}$ dos 26 aos $46 \mathrm{DAT}$, especialmente no $2^{\circ}$ ciclo, sendo que a difusão e a sua absorção são favorecidas
* Abaixo do limite de detecção; ** Análise não realizada; 1Fonte: PAGANINI (1997), CE = condutividade elétrica, SDT (mg.L-1) = CE (dS.m-1) x 640. 
pela manutenção de alta concentração deste nutriente na solução do solo e pela ausência de impedimentos físico e químico, fatores que podem ter influenciado nos resultados obtidos, como também observado por Costa et al. (2009). Duarte et al. (2008) observou teores médios de potássio trocável no solo ao final de um ciclo da cultura do pimentão igual a 0,21 cmolc dm-3 para a água residuária filtrada por filtro de areia e discos, inferior aos obtidos neste trabalho. De acordo com Raij et al. (2001) teores de potássio trocável no solo acima de 6 mmolc $\mathrm{dm}^{-3}$ são considerados altos; entretanto, para exercer efeito deletério quanto à disponibilidade de cálcio e magnésio às plantas é necessário que as relações K/Ca e K/Mg estejam em desequilíbrio.

$\mathrm{O} \mathrm{Na}{ }^{2+}$ foi o elemento químico que apresentou maior elevação no solo, considerando o valor aos 6 em relação ao 46 DAT (Tabela 3), sendo que no $1^{\circ}$ ciclo chegou a $188 \%$ no gotejamento subsuperficial para a camada de $0-0,10 \mathrm{~m}$ e de $166 \%$ na camada de $0,10-0,20 \mathrm{~m}$. Notou-se tendência de elevação progressiva de $\mathrm{Na}$ nas três épocas de coleta de solo (6, 26 e 46 DAT) em todos os tratamentos e nas duas camadas de solo; concluiuse que pode ter ocorrido que os teores de Na presente na água residuária tenham sido superiores à capacidade de absorção pela alface, promovendo acúmulo deste íon no solo, independente do sistema de irrigação, sendo mais evidente no $1^{\circ}$ ciclo, enquanto que no $2^{\circ}$ ciclo foi menos acentuado, possivelmente pela maior lixiviação, tanto pela água de irrigação como pela precipitação natural, que foi maior neste ciclo, acúmulo de Na trocável ao longo do tempo nos tratamentos irrigados, também foi comprovado por Leal et al. (2009).

Observou-se, no $1^{\circ}$ ciclo, aumento significativo na concentração de NT, dos 6 aos 46 DAT nos tratamentos Ar, Gbd, Gpr e Gpd na camada de solo de 0-0,10 m e nos tratamentos Ar, Ad, Gpr e Gpd na camada de solo de 0,10-0,20 m (Tabela 3). Medeiros et al. (2005) ao contrário, não detectaram aumentos nas concentrações de NT com a aplicação de água residuária doméstica bruta, filtrada com filtro de areia e de disco e aplicada por gotejamento durante o período de 270 dias. No $2^{\circ}$ ciclo a elevação foi significativa dos 27 aos 49 DAT nos tratamentos Ar, Gbr, Gbd e Gpr na camada de solo de 0-0,10 m, sendo maior no solo irrigado com água residuária na aspersão e gotejamento superficial. As elevações de NT sejam no $1^{\circ}$ ou no $2^{\circ}$ ciclos, são devidas à grande quantidade de $\mathrm{N}$ na água de

Flgura 2 - Sistema de captação, tratamento e distribuição da água residuária aos sistemas de irrigação por aspersão, gotejamento subterrâneo e superficial.
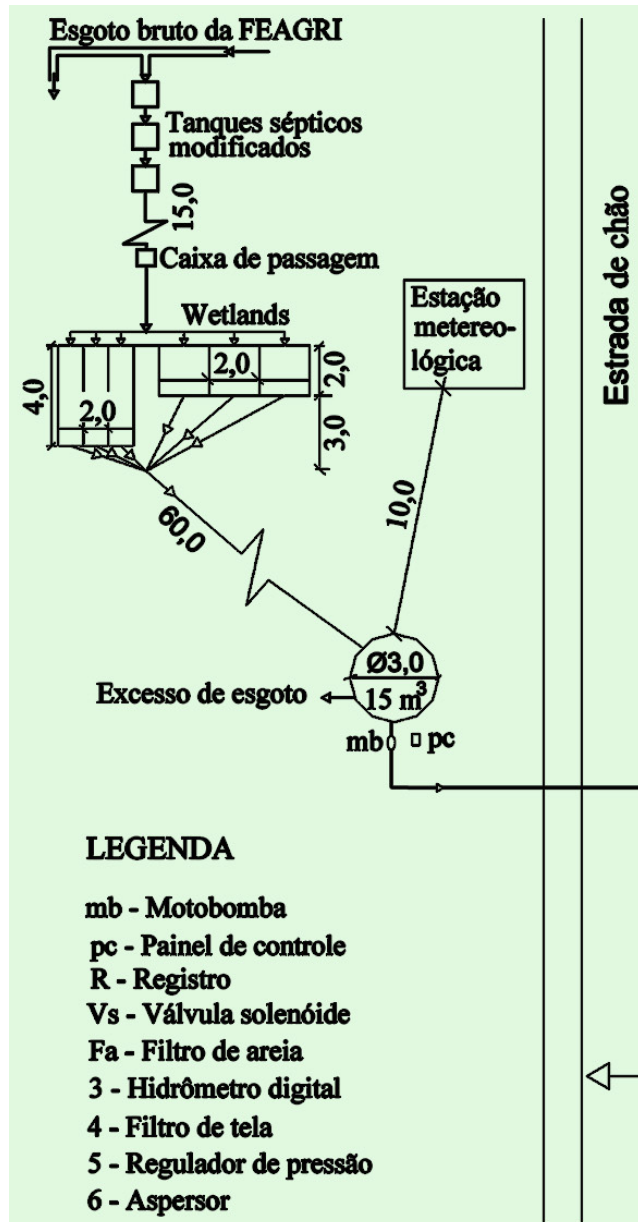

Unidade em metros

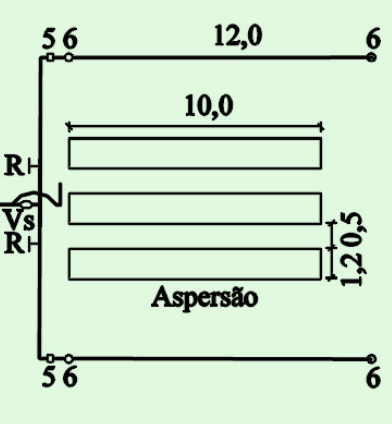

4

115,0

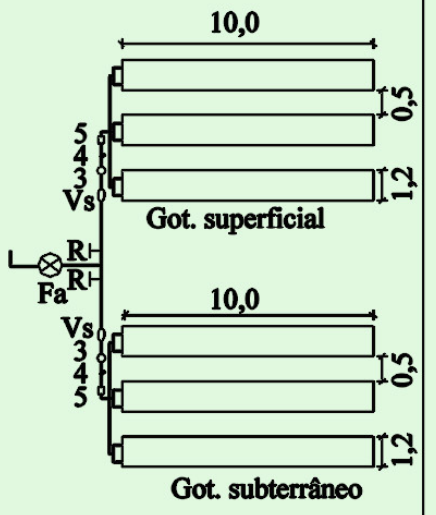


Tabela 3 - Valores médios de fósforo, potássio, nitrogênio total e sódio no solo irrigado com os tratamentos avaliados. irrigação como pela aplicação em cobertura de sulfato de amônia.

\begin{tabular}{|c|c|c|c|c|c|c|c|c|c|c|c|c|}
\hline & \multicolumn{12}{|c|}{ Tratamentos } \\
\hline & $\mathrm{Ar}$ & $\mathrm{Ad}$ & Gbr & Gbd & Gpr & Gpd & & $\mathrm{Ar}$ & $\mathrm{Ad}$ & Gbr Gbd & Gpr & $\overline{\mathrm{Gpd}}$ \\
\hline & \multicolumn{7}{|c|}{$1^{\circ} \mathrm{Ciclo}$} & \multicolumn{5}{|c|}{$2^{\circ}$ ciclo } \\
\hline \multirow[b]{2}{*}{ DAT } & \multicolumn{12}{|c|}{ Fósforo $\left(\mathrm{mg} \mathrm{dm}^{-3}\right)$} \\
\hline & \multicolumn{5}{|c|}{ Camada de $0-0,10 \mathrm{~m}$} & \multicolumn{2}{|r|}{ DAT } & \multicolumn{4}{|c|}{ Camada de $0-0,10 \mathrm{~m}$} & \\
\hline 6 & $7 a$ & & & $32,3 a$ & 4 & 40,3a & & a & & & 5,0 & \\
\hline 26 & & & & & & $57,0 a$ & 2 & & & & & \\
\hline \multirow[t]{2}{*}{46} & & 56 & & 34,3 & & $46,0 a$ & 49 & & & & & 48,3 \\
\hline & \multicolumn{12}{|c|}{ Camada de $0,10-0,20 \mathrm{~m}$} \\
\hline 6 & , Oa & $32,0 \mathrm{~b}$ & $50,3 a$ & 36,0 & $41,3 a^{3}$ & $35,7 a$ & 7 & $51,3 a$ & 4 & $a$ & 41 & 47,0 \\
\hline 26 &, $7 a$ & & & $25,7 a$ & $4 \varsigma$ & $44,0 a$ & 2 & & & & & 39 \\
\hline \multirow[t]{2}{*}{46} & & & & & & $51,0 a$ & 45 & & & & & \\
\hline & \multicolumn{12}{|c|}{ Potássio $\left(\mathrm{cmol} \mathrm{dm}^{-3}\right)$} \\
\hline 6 & & $0,49 \mathrm{~b}$ & & $0,45 a$ & 0, & a $0,63 a$ & 7 & $0,33 a$ & & $0 \mathrm{a}$ & & 0,4 \\
\hline 26 & & & & & & 0, & & & & & & \\
\hline \multirow[t]{2}{*}{46} & & & & & $5 a$ & a $0,44 a$ & & & & & & \\
\hline & \multicolumn{12}{|c|}{ Camada de $0,10-0,20 \mathrm{~m}$} \\
\hline 6 & & & & & $0,43 a$ & a $0,63 a$ & 7 & 030 & 0,6 & & & \\
\hline 26 & & 0,6 & & $0,45 a$ & $0,52 a$ & a $0,49 a$ & 27 & & & & & \\
\hline \multirow[t]{2}{*}{46} & & 0,6 & & $0,44 a$ & $0,45 a$ & a $0,48 a$ & 49 & $0,30 a$ & $0,50 a$ & $\mathrm{Oa}$ & 0 & 0 \\
\hline & \multicolumn{12}{|c|}{ Nitrogênio total $\left(\mathrm{cmol} \mathrm{dm}^{-3}\right)$} \\
\hline 6 & $8 b$ & & $0 \mathrm{a}$ & $1,8 b$ & $1,8 b$ & $2,0 \mathrm{~b}$ & & $9 a b$ & & $9 a b$ & $4 a b$ & $3,0 a$ \\
\hline 26 & $2,7 a$ & $2,7 a$ & $2,8 a$ & $2,3 a$ & $2,6 a$ & $3,4 a$ & & & ta & $, 0 b \quad 2,0 b$ & $2,0 \mathrm{~b}$ & $2,4 a$ \\
\hline 46 & & $2,4 a$ & $2,6 a$ & $2,6 a$ & $2,8 a$ & $3,2 a$ & & & $3,2 a$ & $3,5 a$ &, $4 a$ & \\
\hline \multicolumn{13}{|c|}{ Camada de $0,10-0,20 \mathrm{~m}$} \\
\hline 6 & &, $5 b$ & $2,4 a$ & $2,4 a$ & $1,8 b$ & $2,0 \mathrm{~b}$ & 7 & & $1,8 b$ & ת & & $1,3 b$ \\
\hline 26 & $7 a b$ & $3,0 a$ & $2,1 a$ &, $5 a$ & $2,8 a$ & $3,2 a$ & & & & & $3 \mathrm{~B}$ & 2, \\
\hline 46 & & $2,4 a b$ & 28 & $3,0 \mathrm{a}$ & $2,8 a$ & 3,0 & & & 2,8 & 41 a & $2,8 a$ & 2 \\
\hline \multicolumn{13}{|c|}{ Sódio ( $\mathrm{mg} \mathrm{dm}^{-3}$ ) } \\
\hline 0 & & & & & & $5,2 a$ & & & & & & \\
\hline 26 & & $4,8 a b$ & $10,0 \mathrm{~b}$ & $3,7 a$ & $8,5 \mathrm{ab}$ & b $6,8 a$ & & & & & & 5 \\
\hline 46 & $3 a$ & 6 & 17 & $4,5 a$ & $2,0 a$ & a $6,7 a$ & 49 & $17,2 a$ & $5,0 a$ & $2,9 a$ & $7,1 a$ & 3, \\
\hline \multicolumn{13}{|c|}{ Camada de $0,10-0,20 \mathrm{~m}$} \\
\hline 6 & & & & 4,7 & $7,9 b$ & $4,7 a$ & 7 & & 4 & 3.6 & & 3,7 \\
\hline 26 & & $6,4 a b$ & $11,9 b$ & $5,0 a$ & $9,9 b$ & 5 & 2 & & & 0,0 & & \\
\hline 46 & & & 16 & $5,6 a$ & $15,2 \mathrm{a}$ & a $5,1 \mathrm{a}$ & 48 & $15,3 a$ & $5,0 \mathrm{a}$ & $10,6 \mathrm{a} \quad 3,8 \mathrm{a}$ &, $5 a$ & $3,5 a$ \\
\hline
\end{tabular}

O teor do $\mathrm{Mn}^{2+}$ do solo, de maneira geral (Tabela 4), no $1^{\circ}$ ciclo em ambas as camadas de solo, apresentou tendência de elevação até aos 26 DAT e diminuição em relação aos 46 DAT, influenciada, possivelmente, pela absorção pelas plantas, uma vez que em ambos os tipos de água sempre se mantiveram abaixo do limite de detecção do equipamento utilizado nas análises, sendo significativo entre no início e final do $1^{\circ}$ ciclo nos tratamentos $\mathrm{Ar}$, Ad e Gpr na camada de solo de 0-0,10 m. A disponibilidade do $\mathrm{Mn}^{2+}$ no solo depende, sobretudo do $\mathrm{pH}$, do potencial de oxi-redução, da matéria orgânica e do equilibro com outros cátions, como o ferro, cálcio e magnésio.

$\mathrm{O}$ teor de $\mathrm{Ca}^{2+}$ no solo de maneira geral apresentou tendência de redução (Tabela 4), que segundo Jnad et al. (2001), pode ser devida à reação do $\mathrm{Ca}^{2+}$ com carbonato e sulfato presentes em alta concentração em efluentes e em virtude, também, a sua precipitação.

Observa-se, no $1^{\circ}$ ciclo, elevação significativa no Mg dos 6 aos 46 DAT no tratamento Ad em ambas as camadas, sendo estas de $25 \%$; já no $2^{\circ}$ ciclo, se constatou elevação no teor Médias seguidas por letras distintas na coluna diferem entre si a nível de de $\mathrm{Mg}$ somente no tratamento $\mathrm{Ar}$, dos 7 as 49 DAT na $10 \%$ de de significância.

Ar - Aspersão com água residuária, Ad - aspersão com água do depósito, Gbr - gotejamento subterrâneo com água residuária, Gbd - gotejamento subterrâneo com água do depósito, Gpr - gotejamento superficial com água residuária e Gpd - gotejamento superficial com água do depósito camada de solo de 0,10-0,20 m, de 20\%. Jnad et al. (2001), constataram que o teor de Mg foi sempre mais elevado no solo irrigado com efluente com tratamento secundário, que no solo controle, em todos os pontos analisados.

Figura 3 - Sistema de captação e distribuição da água do depósito superficial aos sistemas de irrigação por aspersão, gotejamento subterrâneo e superficial.

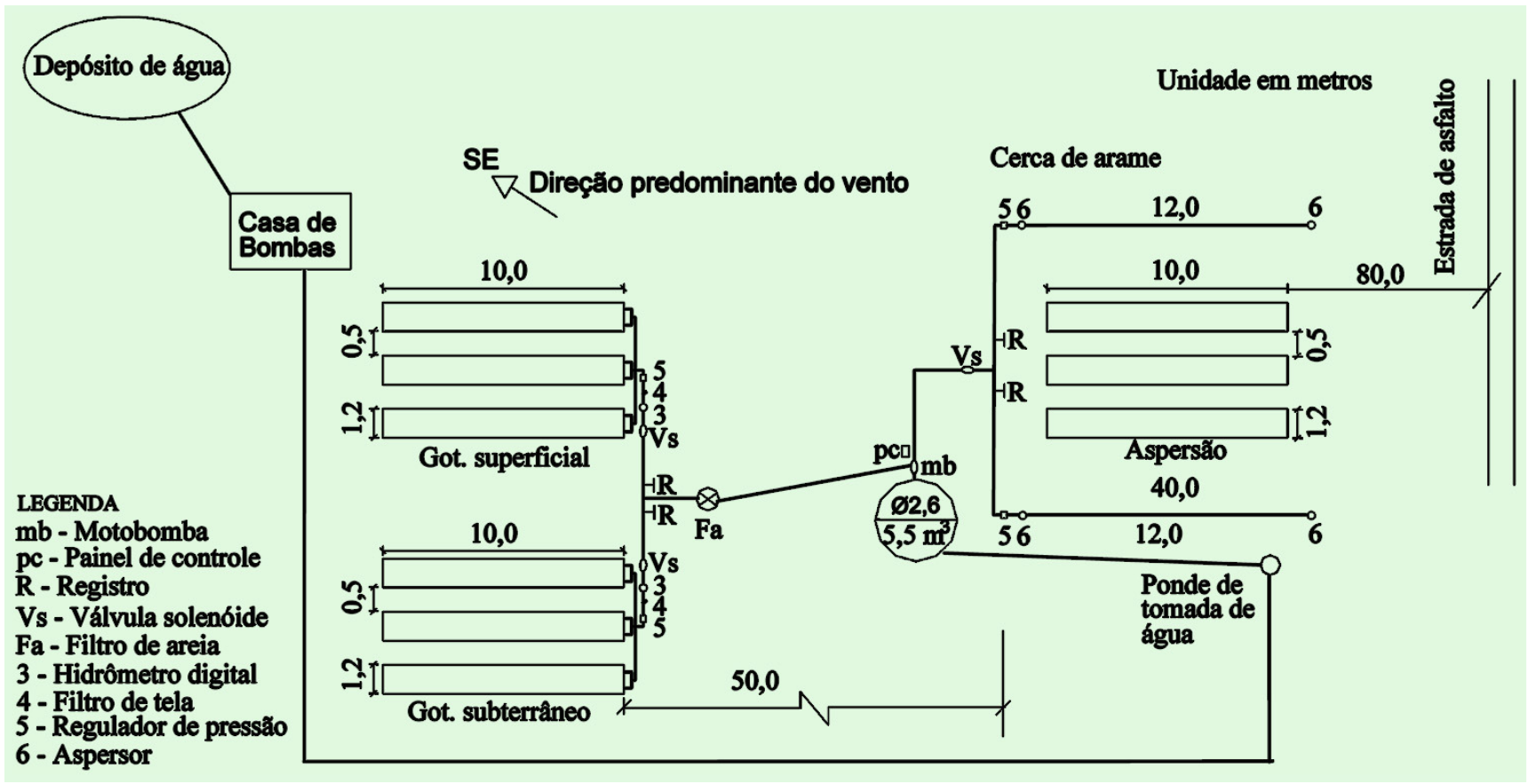


Tabela 4 - Valores médios de cálcio, manganês, magnésio e condutividade elétrica no solo irrigado com os tratamentos avaliados. apresentou elevação no $1^{\circ}$ ciclo no solo irrigado com água residuária, em ambas as camadas avaliadas na aspersão e gotejamento superficial. Os sistemas de irrigação utilizados para aplicação de água residuária mantiveram os constituintes químicos do solo dentro dos limites aceitáveis para o bom desenvolvimento da cultura da alface, não apresentando, de maneira geral, evidente correlação entre as variações observadas dos parâmetros químicos do solo com os sistemas de irrigação.

\section{AGRADECIMENTOS}

À FAPESP, pelo auxílio concedido, e à Faculdade de Engenharia Agrícola, UNICAMP.

\section{REFERÊNCIAS}

ANDRADE NETO, C.O. O uso de esgotos sanitários e efluentes tratados na irrigação. In: Congresso Nacional de Irrigação e Drenagem, 9, 1991, Natal, Anais... Natal: Abid, p.1961-2006, Natal, RN, 1992.

ARMON, R.; DOSORETZ, C.G.; AZOV, Y.; SHELEF, $G$. Residual contamination of crops irrigated with effluent of different qualities: A field study. Water Science and Technology, v.30, n.9, p.239-248, 1994.

AYERS, R.S.; WESTCOT, D.W. A qualidade da água na agricultura. 2.ed. Campina Grande: UFPB, 1991. agosto/09 Médias seguidas por letras distintas na coluna diferem entre si a nível de $10 \%$ de de significância.

Ar - Aspersão com água residuária, $\mathrm{Ad}$ - aspersão com água do depósito, Gbr - gotejamento subterrâneo com água residuária, Gbd - gotejamento subterrâneo com água do depósito, Gpr - gotejamento superficial com água residuária e Gpd - gotejamento superficial com água do depósito

A condutividade elétrica, de maneira geral, não apresentou variações significativas (Tabela 4), no entanto, houve pequenas oscilações, atribuídas ao $\mathrm{Na}^{2+}$, que atua sobre a dispersão das partículas, que depende do teor total eletrolítico na solução do solo, sendo que o aumento da salinidade reduz o potencial de dispersão do solo devido ao aumento de sodicidade (JNAD et al., 2001).

De uma maneira geral a irrigação com água residuária manteve os elementos químicos do solo dentro dos limites aceitáveis para o bom desenvolvimento da cultura da alface nos três sistemas de irrigação avaliados.

\section{CONCLUSÕES}

O íon sódio foi o que apresentou maior elevação de seu teor no solo irrigado com água residuária em ambas as camadas de solo, sendo maior no sistema de irrigação por gotejamento subsuperficial. No $1^{\circ}$ ciclo o manganês apresentou elevação nos tratamentos Ar e Gpr na camada de solo de 0-0,10 m. O nitrogênio total 218p. Estudos da FAO: Irrigação e Drenagem, 29 Revisado 1.

BASTOS, R.K.X.; ANDRADE NETO, C.O.; CORAUCCI FILHO, B.; MARQUES, M.O. Introdução. In: Utilização de esgotos tratados em fertirrigação, hidroponia e piscicultura. BASTOS, R.K.X (coordenador). Rio de Janeiro: ABES, RiMa. Projeto Programa de Saneamento Básico - PROSAB. 2003. 267p.

COSTA, J. P. V.; BARROS, N. F.; BASTOS, A. L.; ALBUQUERQUE, A. W. Fluxo difusivo de potássio em solos sob diferentes níveis de umidade e de compactação. Revista Brasileira de Engenharia Agrícola e Ambiental. v.13, n.1, p.56-62, 2009.

KOURAA, A.; FETHI, F.; LAHLOU, A.; OUAZZANI, N. Reuse of urban wastewater by combined stabilization pond system en Benslimane (Marocco). Urban Water, v.4, p.373-378, 2002.

DUARTE, A.S.; AIROLDI, R.P.S.; FOLEGATTI, M.V.; BOTREL, T.A. SOARES, T.M. Efeitos da aplicação de efluente tratado no solo: $\mathrm{pH}$, matéria orgânica, fósforo e potássio. Revista Brasileira de Engenharia Agrícola e Ambiental, Campina Grande, PB, v.12, n.3, p.302-310, 2008.

FAO. Irrigation water management: irrigation methods, Series title: Irrigation water management, Training manuals 5. 1988. Disponível em :http://www.fao.org/docrep/S8684E/ s8684e01.htm\#preface.Acesso: 15 de Junho de 2009.

FEIGIN, A.; RAVINA, I.; SHALHEVET, J. Irrigation with treated sewage effluent: management for environmental protec- 
tion. Berlin: Springer, 1991. 224p.

FRIEDLER, E.; JUNIACO, M. Tratament and storage of wastewater for agricultural irrigation. Agritech/1996 (Agronitech Technology Ltda.). Tel-Aviv, Israel, 1996.

JNAD, I.; LESIKAR, B.; KENIMER, A.; SABBAGH, G. Subsurface drip of residential effluent: I. soil chemical characteristics. Transaction of the ASAE, St. Joseph. v.44, n.5, p.11491157, 2001.

LEAL, R.M.P.; FIRME, L.P.; MONTES, C.R.; MELFI, A.J.; PIEDADE, S.M. De S. Soil exchangeable cations, sugarcane production and nutrient uptake after wastewater irrigation. Sci. Agric. (Piracicaba, Braz.), v.66, n.2, p.242-249, March/April 2009.

MEDEIROS, S.S.; SOARES, A.A.; FERREIRA, P.A.; SOUZA, J.A.A.; SOUZA, J.A.; MATOS, A.T. Comportamento dos atributos químicos do solo em resposta à aplicação de água residuária de origem doméstica. Revista Brasileira de Engenharia Agrícola e Ambiental, Campina Grande, PB, v.9, (Suplemento), p.268-273, 2005.

NEILSEN, G.H.; STEVENSON, D.S.; FITZPATRICK, J.J.; BROWNLLE, C.H. Yield and plant nutrient content of vegetbles trickle-irrigated with municipal wastewater. HortScience. v.24, n.2, p.249-252, 1989.

PAGANINI, W.S. Disposição de esgotos no solo: Escoamento à superfície. São Paulo. AESABESP, 1997. 232p.

RAIJ, B. van; ANDRADE, J.C.; CANTARELLA, H.; QUAGGIO, J.A. Análise química para avaliação da fertilidade de solos tropicais. 4. ed. Campinas: Fundação Cargill, 2001, 343p.

SCALOPPI, E. J.; BAPTISTELLA, M J. R. Considerações sobre a aplicação de efluentes ao solo. In: Congresso Nacional de Irrigação e Drenagem. 12, Anais... Brasília, p.1049-1067, 1986.

SILVA, F.B. Manual de análises químicas de solos, plantas e fertilizante. Brasília: Embrapa Comunicação para Transferência de Tecnologia, 1999. 370p.

STEIN, J.L.; SCHWARTZBROD, J. Experimental Contamination of vegetables with Helminth Eggs. Water Science and Technology. v.22, n.9, p.51-57, 1990.

TARCHITZKY, J.; LERNER, O.; SHANI, U.; RYE, G.; LOWENGART-AYCICEGI, A.; BRENER, A.; CHEN, Y. Water distribution pattern in treated wastewater irrigated soils: hydrophobicity effect. European Journal of Soil Science, v.58, n.3, p.573-588, 2007.

TRANI, P.E. Hortaliças folhosas e condimentos. In: PEREIRA, M.E.; CRUZ, M.C.P.; van RAIJ, B.; ABREU, C.A. (ed.) Micronutrientes e elementos tóxicos na agricultura. Jaboticabal: CNPq/FAPESP/ POTAFOS, 2001, p.293-510.

TRANI, P.E.; RAIJ, B. Van. Hortaliças. 2.ed. Campinas: IAC, 1997. p.30-36. (Boletim Técnico, 100). 